\title{
RAPID COGNITIVE DECLINE, ONE-YEAR INSTITUTIONAL ADMISSION AND ONE-YEAR MORTALITY: ANALYSIS OF THE ABILITY TO PREDICT AND INTER-TOOL AGREEMENT OF FOUR VALIDATED CLINICAL FRAILTY INDEXES IN THE SAFES COHORT
}

\author{
M. DRAME1,2, J.-L. NOVELLA ${ }^{1,2}$ D. JOLLY1,3, I. LANIECE4 ${ }^{4}$, D. SOMME5 , D. HEITZ6 , J.-B. GAUVAIN7, \\ T. VOISIN", B. DE WAZIERES ${ }^{9}$, R. GONTHIER ${ }^{10}$, C. JEANDEL ${ }^{11}$, P. COUTURIER ${ }^{4}$, O. SAINT-JEAN5, \\ J. ANKRI ${ }^{12}$, F. BLANCHARD ${ }^{1,2}$, P.-O. LANG ${ }^{1}$
}

\begin{abstract}
1. University of Reims Champagne-Ardenne, Faculty of Medicine, E.A 3797, Reims, F-51092, France; 2. Reims Teaching Hospitals, Maison Blanche Hospital, Department of Clinical Gerontology, Reims, F-51092, France; 3. Reims University Hospitals, Robert Debré Hospital, Clinical Research Coordination Unit, Reims, F-51092, France; 4. Grenoble University Hospitals, Hospital of La Tronche, Geriatrics Department, Grenoble, F-38700, France; 5. Public Assistance - Hospitals of Paris, Georges Pompidou European Hospital, Geriatric Department, Paris, F-75905, France; 6. Strasbourg University Hospitals, Hospital of La Robertsau, Department of Internal Medicine and Geriatrics, Strasbourg, F-67015, France; 7. Regional Hospitals of Orléans, Hospital of Porte Madeleine, Geriatrics Centre, Orléans, F-45032, France; 8. Toulouse University Hospitals, Rangueil Hospital, Department of Internal Medicine and Clinical Gerontology, Toulouse, F-31400, France; 9. Nîmes University Hospitals, Gaston Doumergues Hospital, Department of Internal Medicine and Geriatrics, Nîmes, F30029, France; 10. Saint Etienne University Hospitals, Hospital of La Charité, Department of Clinical Gerontology, Saint Etienne, F-42055, France; 11. Montpellier University Hospitals, Hospital of La Colombière, Clinical Gerontology Centre, Montpellier, F-34295, France; 12. Public Assistance - Hospitals of Paris, Sainte-Perine Hospital, Centre of Gerontology, Paris, F-75015, France; 13. University Hospitals and Medical school of Geneva, Department of Internal Medicine, Rehabilitation and Geriatrics, Geneva, CH-1226, Switzerland. Correspondence: Pierre Olivier Lang, MD, MPH, PhD. Department of Internal Medicine, Rehabilitation and Geriatrics, Hospital of Trois-Chêne, Chemin du Pont-Bochet, 3 - CH-1226 Thônex-Geneva, Switzerland, Phone: + 41223056111 - fax: + 41223056115 -E-mail: pierre.o.lang@ hcuge.ch
\end{abstract}

\begin{abstract}
Objectives: To evaluate the predictive ability of four clinical frailty indexes as regards one-year rapid cognitive decline (RCD - defined as the loss of at least 3 points on the MMSE score), and one-year institutional admission (IA) and mortality respectively; and to measure their agreement for identifying groups at risk of these severe outcomes. Design: One-year follow-up and multicentre study of old patients participating in the SAFEs cohort study. Setting: Nine university hospitals in France. Participants: 1,306 patients aged 75 or older (mean age $85 \pm 6$ years; $65 \%$ female) hospitalized in medical divisions through an Emergency department. Measurements: Four frailty indexes (Winograd; Rockwood; Donini; and Schoevaerdts) reflecting the multidimensionality of the frailty concept, using an ordinal scoring system able to discriminate different grades of frailty, and constructed based on the accumulation of identified deficits after comprehensive geriatric assessment conducted during the first week of hospital stay, were used to categorize participants into three different grades of frailty: G1 - not frail; G2 - moderately frail; and G3 - severely frail. Comparisons between groups were performed using Fisher's exact test. Agreement between indexes was evaluated using Cohen's Kappa coefficient. Results: All patients were classified as frail by at least one of the four indexes. The Winograd and Rockwood indexes mainly classified subjects as G2 (85\% and 96\%), and the Donini and Schoevaerdts indexes mainly as G3 (71\% and 67\%). Among the SAFEs cohort population, 250, 1047 and 1,306 subjects were eligible for analyses of predictability for RCD, 1-year IA and 1-year mortality respectively. At 1 year, 84 subjects (34\%) experienced RCD, 377 (36\%) were admitted into an institutional setting, and 445 (34\%) had died. With the Rockwood index, all subjects who experienced RCD were classified in G2; and in G2 and G3 when the Donini and Schoevaerdts indexes were used. No significant difference was found between frailty grade and RCD, whereas frailty grade was significantly associated with an increased risk of IA and death, whatever the frailty index considered. Agreement between the different indexes of frailty was poor with Kappa coefficients ranging from -0.02 to 0.15 . Conclusion: These findings confirm the poor clinimetric properties of these current indexes to measure frailty, underlining the fact that further work is needed to develop a better and more widely-accepted definition of frailty and therefore a better understanding of its pathophysiology.
\end{abstract}

Key words: Frailty syndrome, frailty index, screening, comprehensive geriatric assessment, SAFES cohort.

\section{Introduction}

Global populations are ageing and over the last few decades, there has been a rapid increase in the absolute and relative numbers of older people in both developing and developed countries. This trend will even accelerate over the next two or three decades (1). While this demographic transition presents many opportunities, population ageing confronts our societies with enormous challenges, such as the need to adapt and organize healthcare and psychosocial care for aged individuals $(2,3)$. Indeed, once admitted to hospital, older patients are at risk of functional, physical, and cognitive impairment, which can lead to loss of autonomy, and generally results in a burden for the family, a need for professional helps, admission into an institutional setting, or even death (4-10).

It has been established that frailty is a significant and independent risk factor for disability, institutional admission (IA) and mortality $(5,11-14)$. A notable characteristic of frailty is that not all frail individuals experience the same symptoms, and frailty can be present in the absence of any specific diseases, although it is more likely in combination with, or as a consequence of co-morbidity $(5,14,15)$. This means that frailty 


\section{RAPID COGNITIVE DECLINE, ONE-YEAR INSTITUTIONAL ADMISSION AND ONE-YEAR MORTALITY}

is not synonymous with co-morbidity (12). Thus, many authors consider the frailty syndrome as a continuum from normal ageing to a final state of disability and death, reflecting an intermediate but distinct state between these two extremes (12, 16). Furthermore, it seems possible to differentiate frailty, which seems to be reversible, from ageing, which is not $(12,14$, 15). From this point of view, primary interventions could be envisaged for older persons at risk to prevent them from "entering" a state of frailty. Similarly, the implementation of secondary interventions targeting correlates or specific components of frailty could render the frailty syndrome at its initial stages reversible and/or reduce its severe consequences $(5,16,17)$.

Since the population of (frail) elderly people is still growing, and health care utilization among this population is increasing, the prevention of frailty, or the maintenance of or reduction in the level of frailty should take priority among geriatric health care professionals $(2,18-21)$. However, one of the main hindrances is that to date, there is no consensually accepted evaluative outcome instrument able to detect or measure frailty, and usable both in clinical situations and experimental studies $(12,16,21,22)$. Due to similarities and inter-relationships between the frailty process and ageing and age-related chronic disease (15), frailty is often considered as a combination of ageing, disease, and other factors that make some aged people vulnerable $(12,23)$. Thus, from a preventive perspective, in order to postpone or reduce severe consequences of frailty in hospital settings, it is desirable to be able to accurately identify patients at risk as early as possible after their admission and therefore eligible for a specialised geriatric intervention in hospital settings (17). Because, CGA constitutes an effective medical approach to the elderly patients and it is widely used in routine clinical practice $(24,25)$, several screening tools or instruments measuring frailty have been constructed from deficits observed in a structured clinical examination or comprehensive geriatric assessment (CGA) and have been validated $(16,26)$.

Using data from the SAFEs cohort study (Sujet Âgé Fragile : Évaluation et suivi - Frail elderly subjects: evaluation and follow-up), the present study aimed to measure agreement between four validated frailty indexes in indentifying individuals at risk for severe outcomes $(8,10,27,28)$ and their predictive ability for 1 -year rapid cognitive decline, institutional admission and mortality respectively. The four frailty indexes were selected because they cover essential frailty factors accessible through CGA, and reflect the multidimensionality of the concept. Moreover, all four screening tools use an ordinal scoring system that can discriminate different grades of frailty severity.

\section{Methods}

\section{Study population}

The population of the study was the SAFEs cohort. The design, the cohort sampling, and the inclusion and non- inclusion criteria of the SAFEs cohort study have previously been described elsewhere (19). Briefly, 1,306 subjects aged 75 or over were hospitalized through Emergency Departments (ED) in nine teaching hospitals in France. To be eligible, patients were to be 75 or over; to have been hospitalised in a medical ward in the same hospital as the ED to which they were initially admitted. Subjects were not eligible if hospitalisation was into intensive care or surgery, or if admission did not occur after admission to the ED. Each patient included was interviewed and evaluated by a geriatrician familiar with survey procedures. In the course of this interview, patients were informed about the study, prior to signing the consent form. If the clinical status and/or the cognitive status of the patient did not enable informed consent, informed consent was signed by each willing subject and/or their families or legal representative. Follow-up was by telephone interview after 1 and 8 months and by face-to-face interview with the geriatrician 12 months after the inclusion. The Institutional Review Board of the Reims University Hospital (France) approved the study.

\section{Comprehensive Geriatric Assessment (CGA)}

CGA conducted were conducted by the geriatrician, assisted by a member of the healthcare team and/or the patient's main caregiver or both, during the first week of the hospital stay and one year after the inclusion. CGA gathered a large quantity of socio-demographic and clinical data (25). The following sociodemographic characteristics were recorded: age, gender, living location (private home vs. institution) and educational level (primary, secondary or university studies). For individuals assisted at home by an informal caregiver, the caregiver's burden was assessed by the Zarit caregiver burden inventory (29). A score less than 21 indicated presence of a significant burden. Clinical data included several measures. Functional ability was assessed using Katz's activities of daily living (ADL) (30). Dependency for the ADL was defined according to the ability/inability of the subject to perform the following activities: bodily care, dressing, using the toilet, continence, moving about and feeding. Independent or slightly dependent was defined as dependent for none or one item, moderately disabled as dependent for two to four items, and severely disabled as dependent for five or more items. Evaluation of balance disorders and risk of falling was performed using the one-leg standing balance test (31) or by reference to the occurrence of at least one fall in the preceding 12 months. Gait disorders were assessed using the Timed Get-Up and Go test (32). Dementia and delirium syndromes were systematically recorded by a senior geriatrician according to the Diagnostic and Statistical Manual fourth edition (DSM IV) criteria (33). Folstein's MMSE score was used to grade the patient's cognitive state $(34,35)$. The presence of mood disorders or risk of depression was ascertained using the Gilleard Scale (36) with a threshold at 14. Malnutrition or risk thereof was assessed using the Mini Nutritional Assessment Short Form (MNA-SF) and was defined as a score $<12$ (31). The risk of developing 
pressure sores was assessed using the Norton scale: a score of 14 or less indicated a patient at risk (37). The Charlson index (38) was used to define three levels of co-morbidity (39): low ( 0 to 1$)$, medium (2 to 4 ), and high (5 or over). All other medical conditions, medications, as well as sensory problems were also recorded.

\section{Selection of frailty indexes, and measurement of frailty severity}

Based on a review of the literature, four frailty indexes were selected for the present study: Winograd's index (10); Donini's index (27); Rockwood's index (8); and Schoevaerdts's index (28). To be of interest, frailty indexes had to reflect the multidimensionality of the frailty concept, be constructed on the accumulation of identified deficits based on CGA, and use an ordinal scoring system able to discriminate the different levels of frailty severity. The four frailty indexes selected are described in table 1. Based on the results of CGA conducted during the first week of hospitalization by a geriatrician, the 1,306 patients of the SAFEs cohort were categorized according to three grades of severity: (G1) corresponded to individuals who were considered as "not frail"; (G2) those who were identified as being "moderately frail"; and (G3) defined the "severely frail" group. Initially, in the Rockwood's index, individuals were classified into four groups, from Group 0 (absence of frailty) to Group 3 (severely frail) (10). However, the only difference between groups 0 and 1 was bladder incontinence, and urinary incontinence on its own reportedly has significant effect neither on one-year institutional admission nor one-year mortality (10), Group 0 and Group 1 were merged to generate G1.

Table 1

Components of the four frailty indexes

\begin{tabular}{|c|c|c|c|c|}
\hline \multirow[t]{2}{*}{ Index components } & \multicolumn{4}{|c|}{ Frailty index } \\
\hline & $\begin{array}{c}\text { Winograd } \\
\text { (10) }\end{array}$ & $\begin{array}{c}\text { Rockwood } \\
(8)\end{array}$ & $\begin{array}{c}\text { Donini } \\
(27)\end{array}$ & $\begin{array}{c}\text { Schoevaerdts } \\
\text { (28) }\end{array}$ \\
\hline Age & & & - & - \\
\hline Economic/Social problems* & - & & & \\
\hline Living situation & & & & $\bullet$ \\
\hline Perceived Health & & & & $\bullet$ \\
\hline Functional status: Basic ADLs & $\bullet$ & • & $\bullet$ & $\bullet$ \\
\hline Functional status: IADLs & & & & $\bullet$ \\
\hline Balance or risk of falls & $\bullet$ & & & • \\
\hline Cognitive function & $\bullet$ & $\bullet$ & $\bullet$ & - \\
\hline Neuropsychiatric status & • & & & \\
\hline Nutritional status & $\bullet$ & & $\bullet$ & - \\
\hline Pressure sore risk & $\bullet$ & & & \\
\hline Comorbidity & - & & & - \\
\hline Polypharmacy & • & & & - \\
\hline Sensory assessment & - & & & \\
\hline
\end{tabular}

* Physical or mental abuse, financial problems, caregiver stress, no available caregiver, marital stress, placement problems... ADL = Activities of Daily Living; IADL= Instrumental Activities of Daily Living.

\section{End point measures}

The endpoints studied were rapid cognitive decline (RCD); institutional admission (IA) and mortality occurring within the first year of follow-up. RCD was defined, irrespectively of aetiology, as the loss of at least three points at the MMSE score within 1 year from inclusion $(35,40)$. All patients presenting dementia with a minimum score of three on the MMSE and who were followed-up for at least one year were included in the subsequent analyses. Concerning IA, this outcome was defined as incident admission into either a nursing home or other longterm care facilities during the follow-up period of one year (41). Thus, individuals living in an institutional setting at the time of inclusion were not considered for subsequent analyses of this endpoint. The vital status was updated from the hospital wards (using the hospital network data-processing, or by a telephone follow-up) or, if missing, from the appropriate registry department where deaths are systematically registered in France (42).

\section{Statistical analyses}

A descriptive analysis of socio-demographic characteristics and CGA results was performed. Numerical variables are presented as mean \pm standard deviation $( \pm \mathrm{SD})$. For categorical variables, number and percentage are presented. For predictive validity on RCD, IA and mortality, Fisher's test was used to compare percentages of events between frailty grades. The level of significance was set at $p=0.05$. Agreement between the four frailty indexes was estimated using Cohen's Kappa statistic. Agreement was considered as excellent for Kappa values of $0.81-1$; good for $0.61-0.80$; moderate for $0.41-0.60$; slight for 0.21-0.40; and poor for values lower than 0.21 (43). All analyses were performed using SAS software version 9.1 (SAS System, SAS Institute Inc., Cary, NC).

\section{Results}

The socio-demographic characteristics and CGA data from the SAFEs cohort population are presented in table 2. Two thirds of the cohort were females $(64.7 \%)$. The average age was $85.0 \pm 5.9$ (range: 75 to 103 years). As shown in table 3 , the four indexes graded the SAFEs cohort patients differently. The Winograd and Rockwood indexes classified the majority of subjects as G2 (85\% and 96\%, respectively), while the Donini and Schoevaerdts indexes classified patients mainly as G3 (71\% and $67 \%$, respectively).

Among the 1,306 patients in the SAFEs cohort, 250, 1047 and 1,306 subjects were eligible for subsequent analyses of the predictive ability of the frailty indexes for RCD, institutional admission and mortality respectively. Thus, during the one year of follow-up, 84/250 (33.6\%) subjects experienced RCD, $377 / 1047(36.01 \%)$ were admitted into an institutional setting, and $445 / 1,306(34.1 \%)$ died. Whatever the frailty index considered, an increasing level of frailty was associated with an increased risk of IA and death in the year following the frailty screening. No significant associations were found between grade of frailty and RCD. With the Rockwood index, all subjects who presented RCD were classified as G2. With the 


\section{RAPID COGNITIVE DECLINE, ONE-YEAR INSTITUTIONAL ADMISSION AND ONE-YEAR MORTALITY}

Donini and Schoevaerdts indexes, subjects who experienced RCD were identified in both G2 and G3 groups (table 4). The agreement between the different indexes for detection of frailty and severity grading was very poor, with Kappa coefficients ranging from -0.02 to 0.15 (table 5).

Table 2

Baseline Characteristics of the SAFES Cohort

\begin{tabular}{|c|c|c|}
\hline Characteristics & $\mathbf{N}$ & $\%$ \\
\hline Age: 85 and over & 641 & 49.1 \\
\hline Female gender & 845 & 64.7 \\
\hline Living in an institutional setting & 218 & 17.0 \\
\hline \multicolumn{3}{|l|}{ Educational level } \\
\hline Primary & 873 & 71.0 \\
\hline Secondary & 253 & 20.6 \\
\hline University & 104 & 8.4 \\
\hline \multicolumn{3}{|l|}{ Number of Katz's ADL dependencies } \\
\hline $0-1$ & 271 & 21.4 \\
\hline $2-4$ & 347 & 27.4 \\
\hline $5-6$ & 647 & 51.2 \\
\hline Walking difficulties (Timed-up and go test) & 1059 & 81.1 \\
\hline Gait and balance difficulties & 661 & 51.2 \\
\hline Dementia (DSM-IV criteria) & 589 & 45.4 \\
\hline Delirium (DSM-IV criteria) & 261 & 20.1 \\
\hline Depression risk (Gilleard's scale) & 568 & 43.5 \\
\hline Malnutrition risk (MNA-SF) & 1007 & 77.1 \\
\hline Pressure sore risk (Norton's scale) & 524 & 40.2 \\
\hline \multicolumn{3}{|l|}{ Number of co-morbidities (Charlson's index) } \\
\hline 0-1: Low level & 871 & 66.7 \\
\hline 2-4: Medium level & 398 & 30.5 \\
\hline$\geq 5:$ High level & 37 & 2.8 \\
\hline
\end{tabular}

Number of missing data: living location (20), educational level (76), ADLs (41), dementia and delirium syndromes (10), Pressure sore risk (3), walking difficulties (1), gait and balance disorders (15); ADL = Activities of Daily Living; IADL $=$ Instrumental Activities of Daily Living; DSM-IV = Diagnostic and Statistical Manual of Mental Disorders, fourth edition; MNA-SF = Mini nutritional assessment short form.

Table 3

Grades of frailty at the time of inclusion according to the four frailty indexes

\begin{tabular}{|c|c|c|c|c|c|c|}
\hline \multirow[b]{2}{*}{ Frailty indexes } & \multicolumn{2}{|c|}{$\begin{array}{l}\text { Grade } 1 \\
\text { (Not frail) }\end{array}$} & \multicolumn{2}{|c|}{$\begin{array}{c}\text { Grade 2 } \\
\text { (Moderately frail) }\end{array}$} & \multicolumn{2}{|c|}{$\begin{array}{c}\text { Grade } 3 \\
\text { (Severely frail) }\end{array}$} \\
\hline & $\mathbf{n}$ & $\%$ & $\mathbf{n}$ & $\%$ & $\mathbf{n}$ & $\%$ \\
\hline Winograd (10) $(n=1098)$ & 14 & 1.3 & 929 & 84.6 & 155 & 14.1 \\
\hline Rockwood (8) (n=1293) & 50 & 3.9 & 1238 & 95.7 & 5 & 0.4 \\
\hline Donini (27) $(n=1269)$ & 8 & 0.6 & 366 & 28.8 & 895 & 70.6 \\
\hline Schoevaerdts (28) $(n=1228)$ & 122 & 9.9 & 280 & 22.8 & 826 & 67.3 \\
\hline
\end{tabular}

\section{Discussion}

This study of the 1,306 patients from the SAFEs cohort shows that screening for frailty at the beginning of a hospital stay can strongly predict one-year adverse outcomes related to frailty. This cohort is a representative sample of the population of patients aged 75 years or over hospitalised in France, and thus places this study in a pragmatic approach to detection of frailty (2).

The four frailty indexes considered, and constructed on the accumulation of identified deficits based on CGA, were able to predict institutionalisation and mortality during the 12 months of follow-up. Surprisingly, they did not predict RCD. Indeed, a large body of evidence has raised the possibility that physical frailty may be a risk factor for both mild cognitive impairment and/or dementia (44). Physical frailty has been defined according to various criteria, such as non-intentional weight loss (45); lower fat-free-soft tissue mass and lower fat mass (46); a body mass index lower than 21 (47); change in four instrumental activities of daily living performance (48) and more recently, as a composite measure $(5,6,49-52)$. The lack of ability to predict RCD observed in our study could be also explained by a sample effect, due to the heterogeneity and the high level of frailty observed within the SAFEs cohort, as well as the number of events recorded after one year of follow-up ( $n$ $=84$ for RCD). Indeed, $45 \%$ of the cohort presented a dementia syndrome at inclusion, with an average MMSE score of $16 \pm 5$. In a previous study concerning the same 250 demented patients drawn from the SAFEs cohort [35], the initial MMSE score was an independent predictor of RCD in the follow-up period of 12 months. Thus the risk of RCD appeared greater when the initial MMSE score was high.

Interestingly, when RCD was considered as the primary outcome in the SAFEs cohort, a set of social, functional (including levels of autonomy), nutritional and behavioural factors were identified as independent predictors (35). Moreover, several articles based on the SAFEs cohort have confirmed that different identified deficits based on CGA are able to predict the loss of autonomy (18), mortality $(18,42,53$, 54), IA (41), early unplanned readmission (55), RCD (35), and prolongation of hospital stays $(19,56,57)$. Based on recent publications, all these independent factors are considered as being among the essential components on frailty (58-60). Thus, factors such as nutritional status, physical activity, mobility, strength, energy (physical domain), cognition, mood (psychological domain) and social relations/social support (social domain) reflect the multidimensionality of the frailty concept (21).

While controversy continues to exist on the choice of the components to be included in frailty indexes, a recent review conducted by Abellan van Kan highlighted the growing evidence that gait speed could be considered as a single-item frailty screening tool (26). The evaluation of gait speed over a short distance emerges from the literature as a tool with the capacity to identify frail older adults, while slow gait speed has been proven to be a strong predictor for frailty-related adverse outcomes. Still more recently, Xue et al (61), with a median follow-up time of 10 years, showed that monitoring the rate of decline in grip and hip flexion strength may greatly improve the identification of women most at risk of dying.

After 30 years of research on this topic, no clear consensual definition of frailty has yet emerged from the literature, and a large array of models and criteria have been proposed to define the syndrome. Two main definitions based on clusters of components are found in literature: a physical phenotype of frailty proposed by Fried et al (6), comprising a list of five measurable items of functional impairment, which coexists 
Table 4

Incidence rates of rapid cognitive decline, institutional admission and mortality within the year following inclusion in the SAFEs cohort study for each frailty grades defined according to the four validated frailty indexes respectively

\begin{tabular}{|c|c|c|c|c|c|c|c|c|c|c|c|c|}
\hline \multirow[b]{2}{*}{ Frailty indexes } & \multicolumn{3}{|c|}{ Rapid cognitive decline } & \multirow[b]{2}{*}{ p* } & \multicolumn{3}{|c|}{ 1-year Institutionalisation } & \multicolumn{5}{|c|}{ 1-year Mortality } \\
\hline & $\begin{array}{c}\text { G1 } \\
\text { n(\%) }\end{array}$ & $\begin{array}{c}\text { G2 } \\
\mathbf{n}(\%)\end{array}$ & $\begin{array}{c}\text { G3 } \\
\text { n (\%) }\end{array}$ & & $\begin{array}{c}\text { G1 } \\
\text { n (\%) }\end{array}$ & $\begin{array}{c}\text { G2 } \\
\mathbf{n}(\%)\end{array}$ & $\begin{array}{c}\text { G3 } \\
\mathbf{n}(\%)\end{array}$ & $\mathbf{p}^{*}$ & $\begin{array}{c}\text { G1 } \\
\text { n }(\%)\end{array}$ & $\begin{array}{c}\text { G2 } \\
\mathbf{n}(\%)\end{array}$ & $\begin{array}{c}\text { G3 } \\
\mathbf{n}(\%)\end{array}$ & $\mathbf{p}^{*}$ \\
\hline Winograd (10) & $2(67)$ & $65(31)$ & $8(42)$ & .25 & $0(0)$ & $275(30)$ & $49(32)$ & .03 & $1(7)$ & $278(30)$ & $73(47)$ & $<.001$ \\
\hline Rockwood (8) & $0(0)$ & $84(34)$ & $0(0)$ & - & $2(4)$ & $370(30)$ & $1(20)$ & $<.001$ & $4(8)$ & $436(35)$ & $3(60)$ & $<.001$ \\
\hline Schoevaerdts (28) & $0(0)$ & $11(37)$ & $71(33)$ & .57 & $11(9)$ & $42(15)$ & 303 (37) & $<.001$ & $3(38)$ & $106(29)$ & $322(36)$ & .05 \\
\hline Donini (27) & $0(0)$ & $7(35)$ & $76(33)$ & .88 & $0(0)$ & $89(24)$ & $282(32)$ & .007 & $10(8)$ & $61(22)$ & $344(42)$ & $<.001$ \\
\hline
\end{tabular}

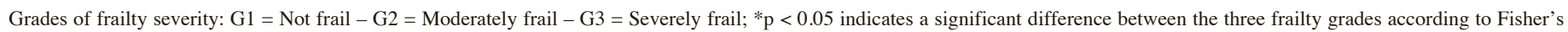
exact test

Table 5

Measurement of the agreement between the four frailty indexes*

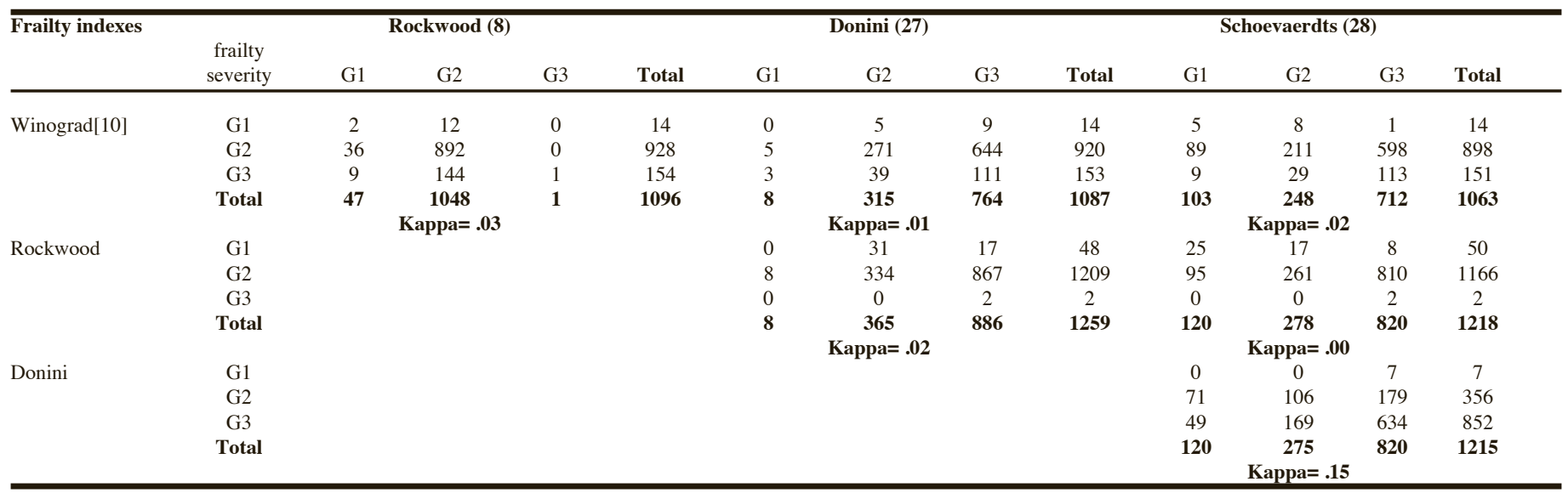

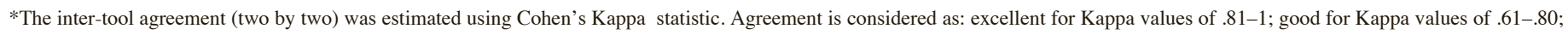

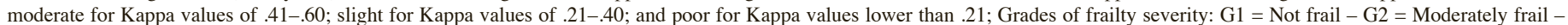
G3 $=$ Severely frail

with a multidomain phenotype, based on frailty indexes constructed on the accumulation of deficits identified by CGA (26). However, controversy continues to exist on the choice of the components or deficits to be included in the definition. Thus a large array of models and criteria has been proposed to define the syndrome and this mainly because the choice of frailty components depends on how frailty is defined $(12,16)$. Alternatively, frailty has been associated with age-related effects on health (62), co-morbidities $(10,62-65)$ or functional disability $(10,66-69)$. Few authors think that age does not have any effect (67), or that frailty is a pre-disability stage, making disability a consequence of frailty rather than its cause (16, 7073 ). Whether disability should be considered in frailty definitions and assessment tools is still widely debated (16).

Recently, an integrated conceptual model of frailty was presented that reflects current thinking and is based on the following definition: "frailty is a dynamic process affecting an individual who experiences losses in one or more domains of human functioning (physical, psychological and social), which is caused by the influence of a range of variables and which increases the risk of adverse outcomes" $(58,59)$. Thus, according to the concept proposed by Fried et al (6), the physical phenotype considers disability and comorbidities (such as dementia) as distinct entities and therefore, outcomes of the frailty syndrome $(12,16,70-73)$, whereas comorbidity and disability can be components of the multidomain phenotype (26). The relationship between frailty and the adverse outcomes usually measured as complications is not direct and covers an intermediate step, which is disability (not only functional, but also psychic and cognitive). Therefore, disability should be considered as the main complication of the frailty process and is itself also the main explanatory factor for institutional admission (41) and/or death (42, 53, 54). However, interestingly, disability is often a core component of frailty indexes, such those used in the present study (see table 1). This probably explains why it has been demonstrated that expanded models of physical frailty, like frailty indexes, over increased the predictive capacity for poor clinical outcomes like institutional admission or mortality, when compared with the predictive capacity of the physical phenotype (26). Indeed, the 


\section{RAPID COGNITIVE DECLINE, ONE-YEAR INSTITUTIONAL ADMISSION AND ONE-YEAR MORTALITY}

grades of frailty severity, as constructed with the frailty indexes used in the present study $(8,10,27,28)$, are more groups of incapacity levels than risk grades of subsequent incapacity. The physical phenotype of frailty proposed by Fried et al and adopted as a working definition by the American Geriatric Society $(6,13)$, constitutes a step further in identifying predisability subjects. Frailty is thus considered as a clinical syndrome, defined by the presence of three or more of the following symptoms: (1) unintentional weight loss (4-5 kg in 1 year); (2) self-reported exhaustion; (3) weakness (grip strength $<20 \%$ in the nondominant hand); (slow walking speed (< $0.65 \mathrm{~m} /$ second) and (5) low physical activity. This phenotype is only based on physical domains and therefore neglects other potentially important components of frailty, such as mood, cognition, sensory impairments and socioeconomic aspects of older adults' lives (12). Furthermore, it is almost impossible to use in routine clinical practice, because it requires knowledge of the underlying population distributions of its components, which also vary with sex and body size $(12,61)$. Moreover, all the defining characteristics or domains defining clinical frailty can also be easily applied to the definition and characterization of the aging process itself and/or age-related diseases $(15,74)$. Thus, from a practical point of view, an earlier identification of the propensity to frailty would be useful to prevent or delay its more severe consequences. Because it may be too late for effective intervention once overt clinical symptoms have already appeared, the most promising parameters for investigations could be biological variables $(14,15,74)$. The results of several large studies clearly demonstrate that increased plasma IL-6 levels, decreased total and HDL cholesterol and insulin-resistance were most strongly associated with the frailty syndrome $(14,15)$. No real association was found with hormones and immunological parameters or with telomere length. However, what effectively triggers the homeostatic failure, whether one or multiple physiological parameters, chronic or acute diseases, is still not clearly established (74). It is therefore not surprising that there is currently no consensus concerning the cause of frailty, probably reflecting the complexity of the multiple interconnected physiological processes which become dysregulated with ageing.

In conclusion, the present study confirms the results of the recent review conducted by de Vries et al (21) concerning the poor clinimetric properties of frailty indexes and current instruments used to evaluate outcome measures of frailty. In addition, while frailty undoubtedly exists as a clinical geriatric syndrome, our results highlight that much further work is required, for a more appropriate and more widely-accepted definition of frailty, and to elucidate the interrelated physiological pathways of frailty. It is only through a comprehensive understanding of the pathophysiological pathways of the frailty process that effective preventive interventions can be properly designed to improve quality of life in the rapidly increasing population of elderly.
Acknowledgments: We are grateful to (1) the French Ministry of Health for funding the Hospital Clinical Research Projects (PHRC 1998), the National Health Insurance Agency for Wage Earners (CNAMTS, France) and the Institute of Longevity and Ageing (Inserm, France); and (2) Fiona Ecarnot for editorial assistance.

Conflict of interest: The authors have no conflicts of interest for this article. The financial sponsors did not play any role in the design, execution, analysis and interpretation of data, or the writing of the manuscript.

\section{References}

1. United Nation Population Division. World population prospects: the 2008 revision population database. 2010. (Accessed February 3rd, 2011, at http://www.un.org/unpd/wpp2008/index.htm.)

2. Lang PO, Dramé M, Jolly D, Novella JL, et al. What do we learn from the SAFEs cohort to fit hospital care models for aged inpatient? Presse Med 2010;39:1132-42.

3. Strandberg TE, Pitkala KH. Frailty in elderly people. Lancet 2007;369:1328-9.

4. Bandeen-Roche K, Xue QL, Ferrucci L, et al. Phenotype of frailty: characterization in the women's health and aging studies. J Gerontol A Biol Sci Med Sci 2006;61:2626.

5. Fried LP, Ferrucci L, Darer J, et al. Untangling the concepts of disability, frailty, and comorbidity: implications for improved targeting and care. J Gerontol A Biol Sci Med Sci 2004;59:255-63.

6. Fried LP, Tangen CM, Walston J, et al. Frailty in older adults: evidence for a phenotype. J Gerontol A Biol Sci Med Sci 2001;56:M146-56.

7. Morley JE, Haren MT, Rolland Y, et al. Frailty. Med Clin North Am 2006;90:83747.

8. Rockwood K, Stadnyk K, MacKnight C, et al. A brief clinical instrument to classify frailty in elderly people. Lancet 1999;353:205-6.

9. Speechley M, Tinetti M. Falls and injuries in frail and vigorous community elderly persons. J Am Geriatr Soc 1991;39:46-52.

10. Winograd $\mathrm{CH}$, Gerety MB, Chung M, et al. Screening for frailty: criteria and predictors of outcomes. J Am Geriatr Soc 1991;39:778-84.

11. Chin APMJ, Dekker JM, Feskens EJ, et al. How to select a frail elderly population? A comparison of three working definition. J Clin Epidemiol 1999;52:1015-21.

12. Lang PO, Michel JP, Zekry D. Frailty syndrome: a transitional state in a dynamic process. Gerontology 2009;55:539-49.

13. Fried LP, Hadley EC, Walston JD, et al. From bedside to bench: research agenda for frailty. Sci Aging Knowledge Environ 2005;2005:pe24.

14. Lang PO, Mitchell WA, Lapenna A, et al. Immunological pathogenesis of main agerelated disease and frailty: role of immunosenscence. European Geriatric Medicine 2010;1:112-21.

15. Fulop T, Larbi A, Witkowski JM, et al. Aging, frailty and age-related diseases. Biogerontology 2010; Epub ahead of print.

16. Abellan van Kan G, Rolland Y, Bergman H, et al. The I.A.N.A Task Force on frailty assessment of older people in clinical practice. J Nutr Health Aging 2008;12:29-37.

17. Somme D, Lazarovici C, Dramé M, et al. The geriatric patient: use of acute geriatrics units in the emergency care of elderly patients in France. Arch Gerontol Geriatr 2011;52:40-5.

18. Lang PO, Meyer N, Heitz D, et al. Loss of independence in Katz's ADL ability in connection with an acute hospitalization: early clinical markers in French older people. Eur J Epidemiol 2007;22:621-30.

19. Lang PO, Heitz D, Hédelin G, et al. Early markers of prolonged hospital stays in older people: a prospective, multicenter study of 908 inpatients in French acute hospitals. J Am Geriatr Soc 2006;54:1031-9.

20. Levers MJ, Estabrooks CA, Roos Kerr JC. Factor contributing to frailty: literature review. J Adv Nurs 2006;44:58-68

21. de Vries NM, Staal JB, van Ravensberg CD, et al, Nijhuis-van der Sanden. Outcome instruments to measure frailty: a systematic review. Ageing Res Rev 2011;10:104-14.

22. De Lepeleire LJ, Iliffe S, Mann E, et al. Frailty: an emerging concept for general practice. Br J Gen Pract 2009;59:e177-e82.

23. Stuck AE, Walhert JM, Nikolaus T, Bula C, Hohmann C, Beck JC. Risk factors for functional status decline in community-dwelling elderly people: a systematic literature review. Soc Sci Med 1999;48:445-69.

24. Stuck A, Egger M, Beck JC. A controlled trial of geriatric evaluation. N Engl J Med 2002;347:371-3.

25. National Institutes of Health. Consensus Development Conference Statement: Geriatrics assessment methods for clinical decision making. J Am Geriatr Soc 1988;36:342-7.

26. Abellan van Kan G, Rolland Y, Houles M, Gillette-Guyonnet S, Soto M, Vellas B. The assessment of frailty in older adults. Clin Geriatr Med 2010;26:275-86.

27. Donini LM, Savina C, Rosano A, et al. MNA predictive value in the follow-up of geriatric patients. J Nutr Health Aging 2003;7:282-93.

28. Schoevaerdts D, Biettlot S, Malhomme B, et al. Identification précoce du profil gériatrique en salle d'urgences : présentation de la grille SEGA. Rev Gériatrie 2004;29 169-76. 


\section{JNHA: FRAILTY AND COGNITIVE DECLINE}

29. Zarit SH, Reever KE, Bach-Peterson J. Relatives of the impaired elderly: correlates of feelings of burden. Gerontologist 1980;20:649-55.

30. Katz S, Akpom CA. A measure of primary sociobiological functions. Int J Health Serv 1976;6:493-508.

31. Vellas BJ, Wayne SJ, Romero L, et al. One-leg balance is an important predictor of injurious falls in older persons. J Am Geriatr Soc 1997;45:735-8.

32. Podsiadlo D, Richardson S. The timed "Up \& Go": a test of basic functional mobility for frail elderly persons. J Am Geriatr Soc 1991;39:142-8.

33. American Psychiatry Association, ed. DSM-IV, Diagnosis and Statistical Manual of Mental Disorders. 4th ed. Washington: American Psychiatry Association; 1994.

34. Folstein MF, Folstein SE, McHugh PR. "Mini-mental state". A practical method for grading the cognitive state of patients for the clinician. J Psychiatr Res 1975;12:189 98.

35. Viatonou S, Dramé M, Jolly D, et al. Predictor of rapid cognitive decline among demented subjects aged 75 or more: ('Sujet Agé Fragile--Evaluation et Suivi' CohortSAFES). Int J Geriatr Psychiatry 2009;24:709-15.

36. Gilleard CJ, Willmott M, Vaddadi KS. Self-report measures of mood and morale in elderly depressives. Br J Psychiatry 1981;138:230-5.

37. Norton D, McLaren R, Exton-Smith A. An investigation of nursing problems in hospitals. New-York: Churchill Livingstone; 1975.

38. Sundararajan V, Henderson T, Perry C, et al. New ICD-10 version of the Charlson comorbidity index predicted in-hospital mortality. J Clin Epidemiol 2004;57:128894.

39. Buntinx F, Niclaes L, Suetens C, et al. Evaluation of Charlson's comorbidity index in elderly living in nursing homes. J Clin Epidemiol 2002;55:1144-7.

40. O'Hara R, Thompson JM, Kraemer HC, et al. Which Alzheimer patients are at risk for rapid cognitive decline? J Geriatr Psychiatry Neurol 2002;15:233-8.

41. Dramé M, Fierobe F, Lang PO, et al. Predictors of Institution Admission in the Year Following Acute Hospitalisation of Elderly People. J Nutr Health Aging 2011;15(5):399-403

42. Dramé M, Novella JL, Lang PO, et al. Derivation and validation of a mortality-risk index from a cohort of frail elderly patients hospitalised in medical wards via emergencies: The SAFES study. Eur J Epidemiol 2008;23:783-91.

43. Cohen J. A coefficient of agreement for nominal scales. Educational Psychological Measurement 1960;20:27-46.

44. Kuh D. A life course approach to healthy aging, frailty, and capability. J Gerontol A Biol Sci 2007;62A:717-21.

45. Barrett-Connor E, Edelstein SL, Corey-Bloom J, et al. Weight loss precedes dementia in community-dwelling older adults. J Am Geriatr Soc 1996;44:1147-52.

46. Nourhashemi F, Andrieu S, Gillette-Guyonnet S, et al. Is there a relationship between fat-free soft tissue mass and low cognitive function? Results from a study of 7,105 women. J Am Geriatr Soc 2002;50:1796-801.

47. Nourhashemi F, Deschamps V, Larrieu S, et al. Body mass index and incidence of dementia: Paquid study. Neurology 2003;60:117-9.

48. Barberger-Gateau P, Dartigues JF, Letenneur L. Four instrumental activities of daily living score as a predictor of one-year incident dementia. Age Ageing 1993;22:45763.

49. Boyle PA, Buchman AS, Wilson RS, et al. Physical frailty is associated with incident mild cognitive impairment in community-based older persons. J Am Geriatr Soc 2010;58:248-55.

50. Ferrucci L, Guralnik JM, Studenski S, et al. Designing randomized, controlled trials aimed at preventing or delaying functional decline and disability in frail, older persons: a consensus report. J Am Geriatr Soc 2004;52:625-34.

51. Mitnitski AB, Song X, Rockwood K. The estimation of relative fitness and frailty in community-dwelling older adults using self-report data. J Gerontol A Biol Sci Med Sci 2004;59:M627-32.
52. Buchman AS, Boyle PA, Wilson RS et al. Frailty is associated with incident Alzheimer's disease and cognitive decline in the elderly. Psychosom Med 2007;69:483-9.

53. Drame M, Dia PA, Jolly D, et al. [Factors predictive of long-term mortality in patients aged 75 years or older hospitalized from the emergency department: the SAFES cohort]. Presse Med 2009;38:1068-75.

54. Drame M, Jovenin N, Novella JL, et al. Predicting early mortality among elderly patients hospitalised in medical wards via emergency department: the SAFES cohort study. J Nutr Health Aging 2008;12:599-604.

55. Lanièce I, Couturier $\mathrm{P}$, Dramé $\mathrm{M}$, et al. Incidence and main factors associated with early unplanned hospital readmission among French medical inpatients aged 75 and over admitted through emergency units. Age Ageing 2008;37:416-22.

56. Lang PO, Zekry D, Michel JP, et al. Early markers of prolonged hospital stay in demented inpatients: a multicentre and prospective study. J Nutr Health Aging 2010;14:141-7.

57. Viatonou S, Dramé M, Jolly D, et al. Predictors of rapid cognitive decline among demented subjects aged 75 or more: ('Sujet Age Fragile--Evaluation et Suivi' CohortSAFES). Int J Geriatr Psychiatry 2009;24:709-15.

58. Gobbens RJ, van Assen MA, Luijkx KG, et al. Determinants of frailty. J Am Med Dir Assoc 2010;11:356-64.

59. Gobbens RJ, Luijkx KG, Wijnen-Sponselee MT, et al. In search of an integral conceptual definition of frailty: opinion of experts. J Am Med Dir Assoc 2010;11:338-43.

60. Katunananthan S, Wolfson C, Bergman H, et al. A multidisciplinary systemic literature review on frailty: overview of the methodology used by the Canadian Initiative on frailty and Aging. BMC Med Res Methodol 2009;68(9).

61. Xue QL, Beamer BA, Chaves PHM, et al. Heterogeneity in rate of decline in grip, hip and knee strength and the risk of all-cause mortality: the women's health and aging study II. J Am Geriatr Soc 2010;58:2076-84.

62. Bortz WM, 2nd. The physics of frailty. J Am Geriatr Soc 1993;41:1004-8.

63. MacAdam M, Capitman J, Yee D, et al. Case management for frail elders: The Robert Wood Johnson Foundation's program for hospital initiatives in long-term care. Gerontologist 1989;29:737-44.

64. Pawlson LG. Hospital length of stay of frail elderly patients. Primary care by general internists versus geriatricians. J Am Geriatr Soc 1988;36:202-8.

65. Williams FM, Wynne H, Woodhouse KW, et al. Plasma aspirin esterase: the influence of old age and frailty. Age Ageing 1989;18:39-42.

66. Gillick M. Long-term care options for the frail elderly. J Am Geriatr Soc 1989;37:1198-203.

67. Kay D. Ageing of the population: measuring the need for care. Age Ageing 1989;18:73-6.

68. Rockwood K, Fox RA, Stolee P, et al. Frailty in elderly people: an evolving concept. Cmaj 1994;150:489-95.

69. Woodhouse KW, Wynne H, Baillie S, et al. Who are the frail elderly? Q J Med 1988;68:505-6.

70. Buchner DM, Wagner EH. Preventing frail health. Clin Geriatr Med 1992;8:1-17.

71. Campbell AJ, Buchner DM. Unstable disability and the fluctuations of frailty. Age Ageing 1997;26:315-8.

72. Chin APMJ, Dekker JM, Feskens EJ, et al. How to select a frail elderly population? A comparison of three working definitions. J Clin Epidemiol 1999;52:1015-21.

73. Fried LP, Waltson JD. Frailty and failure to thrive. In: Hazzard WR, Blass JP, Ettinger WH, Halter JB, Ouslander JG, eds. Principles of geriatric medicine and gerontology. 4th ed. New York: McGraw Hill; 1998:1387-402.

74. Fried LP, Xue QL, Cappola AR et al. Nonlinear multisystem physiological dysregulation associated with frailty in older women: implication for etiologiy and treatment. J Gerontol A Biol Sci Med Sci 2009;64:1049-57. 